\title{
Superselective arterial embolization of the
} superior mesenteric artery for the treatment of gastrointestinal hemorrhage following allogeneic hematopoietic stem cell transplantation

This article was published in the following Dove Press journal:

Patient Preference and Adherence

13 November 2014

Number of times this article has been viewed

\section{Run-Zhe Chen* \\ Gang Zhao* \\ Nan Jin \\ Bao-An Chen \\ Jia-Hua Ding}

Department of Hematology and Oncology, Key Department of Jiangsu Medicine, Zhongda Hospital, Medical School, Southeast University, Nanjing, Jiangsu Province, People's Republic of China

*These authors contributed equally to this work
Correspondence: Bao-An Chen Department of Hematology and Oncology, Zhongda Hospital, Medical School, Southeast University, Dingjiaqiao 87, Gulou District, Nanjing 210009 , Jiangsu Province, People's Republic of China

Tel +862583272006

Fax +86 258327201 I

Email cba8888@hotmail.com

\begin{abstract}
Superselective arterial embolization is a common therapeutic procedure for cases of visceral hemorrhage. However, until now, it has not been applied in the treatment of gastrointestinal (GI) hemorrhage caused by acute graft-versus-host disease (GVHD) after allogeneic hematopoietic stem cell transplantation. We describe a case presenting with persistent GI bleeding associated with acute GVHD successfully treated by superselective arterial embolization of the superior mesenteric artery with gelatin sponge after noneffective conventional management. This case will help guide hematologists to deal with a similar situation in the future.
\end{abstract}

Keywords: gastrointestinal bleeding, acute graft-versus-host disease, allo-hematopoietic stem cell transplantation, arterial embolization

\section{Background}

Acute graft-versus-host disease (GVHD), the immunologic attack of transplanted donor $\mathrm{T}$ lymphocytes against foreign host tissues, is a major complication of allogeneic hematopoietic stem cell transplantation (HSCT). The skin, liver, and gastrointestinal (GI) tract are the main targets of acute GVHD.${ }^{1-4}$ GI tract involvement is less common compared with that of skin and liver ${ }^{1}$ but is recognized as the most severe and difficult to treat, especially GI hemorrhage. ${ }^{2}$ The incidence of GI hemorrhage following bone marrow transplants is approximately $10 \%,{ }^{5}$ and its mortality can reach as high as $30 \%-60 \%$ in patients who experience acute GVHD. ${ }^{6}$ Though overt GI bleeding is uncommon, because of the frequent problem of severe thrombocytopenia, when it occurs, GI bleeding requires prolonged hospitalization and often results in mortality.

Routine therapy for GI bleeding is based on intensive supportive treatment, such as transfusion of blood cells, infusion of coagulation factors, and use of hemostatic agents, ${ }^{7}$ but their effect on controlling severe GI hemorrhage is limited. Where these conservative measures have failed, numerous therapeutic approaches, including endoscopy and surgery, have been tried with little success in patients with hematopoietic malignancies. Recently, a new technique named superselective arterial embolization (SAE) has been attempted in our hospital. SAE is a safe and minimally invasive method used as treatment for severe visceral bleeding and may be especially valuable to patients whose initial conservative therapy is ineffective, or after a failed primary endoscopic approach. However, to the best of our knowledge, there are no publications showing that SAE has been applied to treating GI bleeding caused by acute GVHD following HSCT. Herein, we report a case of a patient with severe GI hemorrhage 
after allogeneic HSCT successfully treated by means of SAE of the superior mesenteric artery.

\section{Case presentation}

A 51-year-old Chinese female presenting with general weakness and pancytopenia for half a year was admitted to our hospital. A complete blood cell count analysis showed mild anemia, with a hemoglobin level of $87 \mathrm{~g} / \mathrm{L}$, white blood cell (WBC) count of $2.35 \times 10^{9} / \mathrm{L}$, and platelet count of $23 \times 10^{9} /$ L. Myelodysplastic syndrome (refractory cytopenia with multilineage dysplasia) was diagnosed by bone marrow examination, and karyotyping revealed 20q-:29.2\% (73/250). After being conditioned with fludarabine, busulfan, highdose cyclophosphamide, and antithymocyte globulin as a preparative regimen, allogeneic peripheral blood stem cell transplantation from her human leukocyte antigen (HLA)matched sibling was performed. Engraftment was apparent on day 16 after transplantation, with total leukocytes recovering, from less than $0.5 \times 10^{9} / \mathrm{L}$ before transplantation to over $1 \times 10^{9} / \mathrm{L}$. Prophylaxis for GVHD consisted of cyclosporin A, Mycophen, and high-dose dexamethasone. Despite these intensive efforts, by day 30 , the patient had developed watery diarrhea, burst oral mucosa, skin rash, and abnormal liver function. Her alanine aminotransferase (ALT) and aspartate aminotransferase (AST) of serum were $301 \mathrm{IU} / \mathrm{L}$ and $106 \mathrm{IU} / \mathrm{L}$, respectively, and her serum albumin was only $28 \mathrm{~g} / \mathrm{L}$, which was lower than the normal value. These symptoms and laboratory indexes strongly suggested the onset of acute GVHD, so the patient was additionally given supporting treatment, including magnesium isoglycyrrhizinate, omeprazole, berberine, and $\mathrm{Smecta}^{\circledR}$, to improve liver function, protect the stomach, and control the symptom of diarrhea.

Cytomegalovirus (CMV) infection was diagnosed at day 80 after transplantation, with the level more than $5 \times 10^{2}$ Copies $/ \mathrm{mL}$, so the patient was treated with ganciclovir. The patient started GI bleeding at day 90, accompanied with abdominal cramping and bloody diarrhea of total 400 to $500 \mathrm{~mL}$ approximately five times per day. Multiple transfusions of red blood cell (RBC) concentrates, platelet, fresh frozen plasma, high-dose prednisolone, broad-spectrum antibiotics, antiviral coverage, and even daily hemostatic agents were utilized. The patient received therapeutic doses of RBC concentrates and platelet transfusions for more than 20 consecutive days after the symptom of bloody diarrhea began. However, despite all these efforts, the bloody diarrhea could not be stopped.

Upper and lower endoscopies were performed, which revealed multiple superficial mucosal lesions of the duodenum and active oozing of blood from the ileocecal junction (Figure 1), and the biopsy specimen revealed lymphocytic duodenitis, which was consistent with GVHD. The problem ahead of us was controlling the severe GI hemorrhage of a patient with $\mathrm{RBC}$ counts less than $3 \times 10^{9} / \mathrm{L}$, hemoglobin level less than $60 \mathrm{~g} / \mathrm{L}$, and platelet counts less than $30 \times 10^{9} / \mathrm{L}$, with a safe method. After careful consideration, we made a bold attempt to introduce the technique of SAE for the treatment of this patient.

The procedure was performed in an angiography room under fluoroscopic guidance. Using local anesthetics, a retrograde catheterization of the left femoral artery was carried out in order to perform digital angiography of the aortoiliac sector, by modified Seldinger's technique. Subsequently, selective catheterization of the celiac artery, with a standard angiographic catheter (Cobra 5F), was carried out to localize the bleeding vessels. Then, the catheter was guided into the superior mesenteric artery at the initial segment of the pancreaticoduodenal artery, where digital subtraction angiography (DSA) showed obvious signs of contrast extravasation, which was confirmed as the bleeding site (Figure 2A). A Progreat ${ }^{\circledR}$ microcatheter was guided into the bleeding branch, and DSA confirmed the previous finding again; then 700 to $1,000 \mu \mathrm{m}$ gelatin sponge microparticles were used to occlude the bleeding branch of the pancreaticoduodenal artery until blood flow was ceased. Subsequently, a further angiography was performed to confirm the occlusion of the bleeding branches (Figure 2B). The catheter was removed after verifying that there were no other bleeding sites. Action of the unilateral lower limb was prohibited for over 12 hours after the angiography.

The patient's GI bleeding stopped following the arterial embolotherapy; there was no further bleeding at the site of embolism and also no clinically obvious bowl necrosis. Two days later, a fecal occult blood test was performed, and the result was negative. The counts of RBCs and hemoglobin also increased gradually, while bloody diarrhea and related symptoms had ceased after treatment and had no recurrence. Though GVHD still existed, the GI hemorrhage had been fully controlled.

\section{Discussion}

GI bleeding is a significant cause of morbidity and mortality of patients suffering from acute GVHD. ${ }^{8}$ Therapy for GI hemorrhage is usually conservative and is accompanied by supportive care, and surgical intervention is rarely needed and generally avoided given the rebleeding risks of the newly transplanted patients. ${ }^{9}$ After ineffective conservative management, 

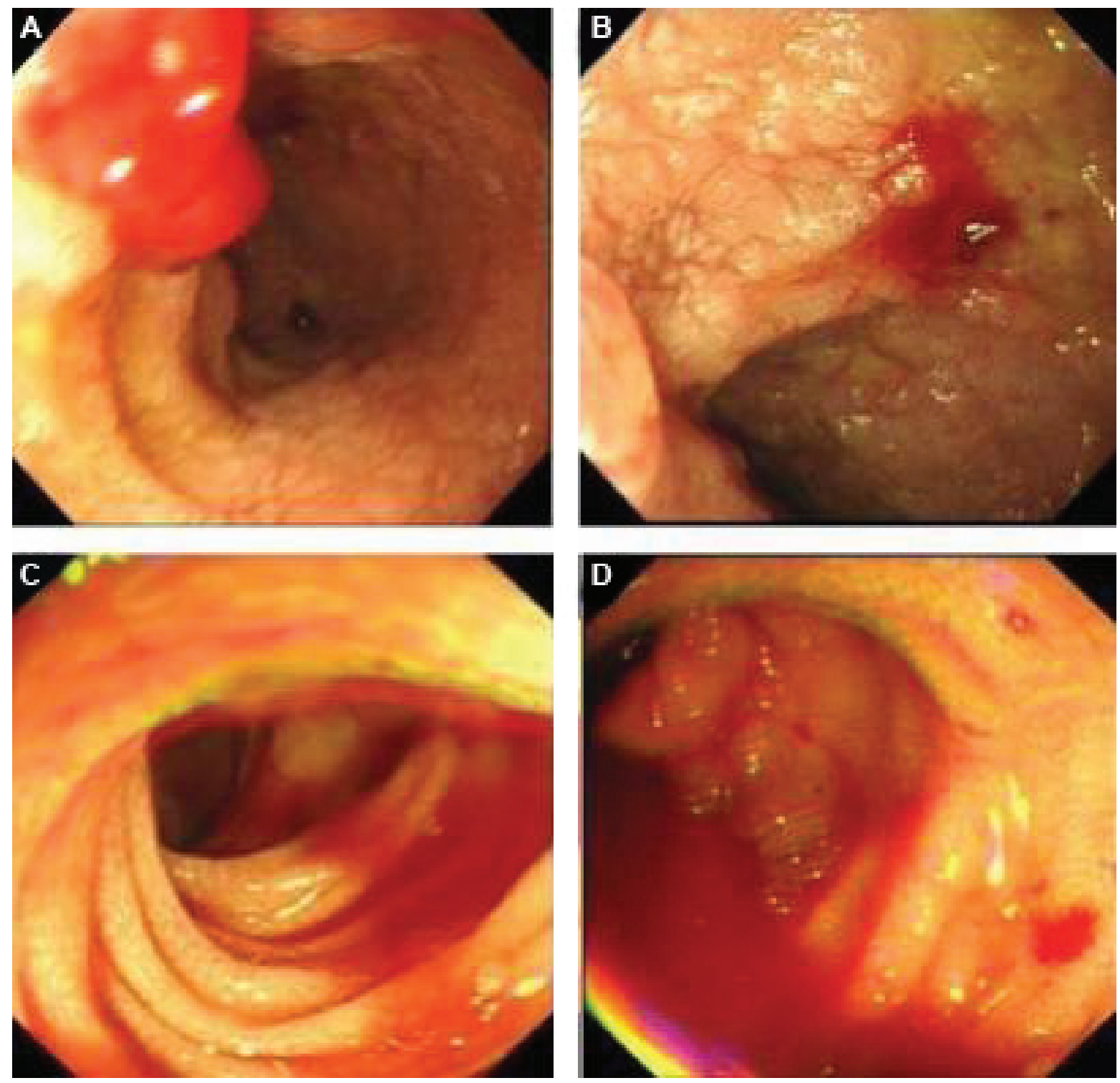

Figure I Endoscopic examinations.

Notes: Gastroscopy showed multiple superficial mucosal lesions of duodenum and diffuse mucosal bleeding (A and B), and colonoscopy indicated active oozing of blood from ileocecal junction (C and $\mathbf{D})$.

we decided to utilize SAE as our treatment option. To our knowledge, this is the first reported case of the use of SAE for controlling GI bleeding secondary to acute GVHD.

These days, SAE plays an increasing role in hemorrhage therapy, and it is an accepted approach for intractable hemorrhage, offering the obvious advantage of a lower rate of morbidity. ${ }^{10,11}$ Several studies have confirmed the role of SAE in controlling GI bleeding. ${ }^{12-23}$ Though endoscopy could also be the choice to establish hemostasis, ${ }^{24}$ this patient's low platelet count (less than $30 \times 10^{9} / \mathrm{L}$ ) and extensive mucosal hemorrhage were the contraindications for endoscopy treatment. Hence, in this case, endoscopy was only used to initially evaluate and diagnose acute GI GVHD.
The reasons for our choices were as follows: firstly, conventional treatment was ineffective for this patient; secondly, the SAE technique is very mature to stop bleeding, in our hospital, for dealing with hemorrhage - though we knew that potential side effects of SAE might occur, the surgeons performing this procedure were all very experienced, having done more than 100 cases per month in our hospital; thirdly, gelatin sponges have been used extensively as an absorbable hemostatic agent with no toxic or antigenic effects on the body.

This case indicated that SAE offers an opportunity for both diagnostics and therapeutics in the management of acute GVHD complicated by GI hemorrhage. However, we should also be careful, throughout the embolization, to 

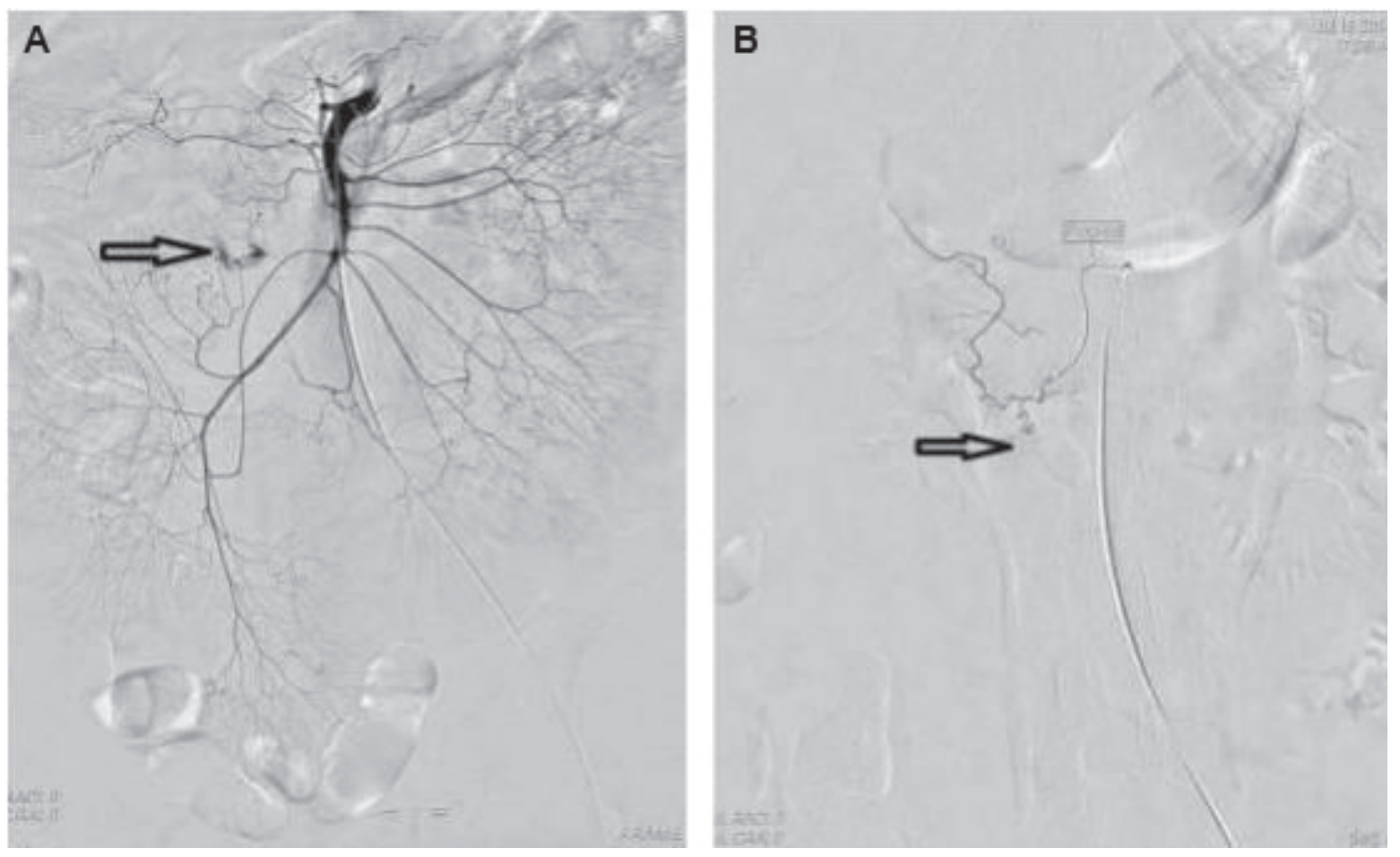

Figure 2 Mesenteric arterial angiography.

Notes: Initial angiography (A) showed a hemorrhage spot in the initial branch of the superior mesenteric artery (indicated by arrow). Selective arterial embolization with gelatin sponge was performed and final angiography (B) demonstrated no signs of arterial bleeding (indicated by arrow).

prevent potential complications, such as fever, hematoma, buttock ischemia, vascular perforation, and infection. Before choosing the technique of SAE, hospital facilities and surgeons' experience should also be considered. What is more, for a better understanding of the therapeutic and adverse effects of SAE in controlling GI hemorrhage after HSCT, a large sample of clinical trial is needed in the future. After this first attempt, we confidently believe that this case will provide a good example and help guide hematologists to deal with a similar situation in the future.

\section{Acknowledgments}

This work was supported by the National Natural Science Foundation of the People's Republic of China (grant numbers 81170492 and 81370673), National High Technology Research and Development Program 863 of the People's Republic of China (grant number 2012AA022703), National Key Basic Research Program 973 of the People's Republic of China (grant number 2010CB732404), Key Medical Projects of Jiangsu Province (grant number BL2014078), and Key Discipline of Jiangsu Province (2011-2015). Gratitude is given to Jos L Campbell at Stanford University for his careful English language editing.

\section{Disclosure}

The authors declare no conflicts of interest in this work.

\section{References}

1. Cantisani V, Mortele KJ, Viscomi SG, Glickman J, Silverman SG, Ros PR. Rectal inflammation as first manifestation of graft-vs-host disease: radiologic-pathologic findings. Eur Radiol. 2003;13 Suppl 4: L75-L 78.

2. Irani JL, Cutler CS, Whang EE, et al. Severe acute gastrointestinal graftvs-host disease: an emerging surgical dilemma in contemporary cancer care. Arch Surg. 2008;143(11):1041-1045; discussion 1046.

3. Castilla-Llorente C, Martin PJ, McDonald GB, et al. Prognostic factors and outcomes of severe gastrointestinal GVHD after allogeneic hematopoietic cell transplantation. Bone Marrow Transplant. 2014;49(7): 966-971.

4. Ertault-Daneshpouy M, Leboeuf C, Lemann M, et al. Pericapillary hemorrhage as criterion of severe human digestive graft-versus-host disease. Blood. 2004;103(12):4681-4684.

5. Kuroiwa Y, Suzuki N, Mizue N, et al. Gastric antral vascular ectasia in 2-yr-old girl undergoing unrelated cord blood stem cell transplantation. Pediatr Transplant. 2005;9(6):788-791.

6. Caronna R, Cardi M, Arcese W, et al. Gastrointestinal surgical emergencies in patients treated for hemathological malignancies. Suppl Tumori. 2005; 4(3):S141-S145.

7. Jiang Q, Huang XJ, Chen $\mathrm{H}$, et al. Severe gastrointestinal bleeding after allogeneic hematopoietic stem cell transplantation - 15 case analysis. Zhonghua Xue Ye Xue Za Zhi. 2005;26(5):277-280. Chinese.

8. Della Porta MG, Alessandrino EP, Bacigalupo A, et al; Gruppo Italiano Trapianto di Midollo Osseo. Predictive factors for the outcome of allogeneic transplantation in patients with MDS stratified according to the revised IPSS-R. Blood. 2014;123(15):2333-2342. 
9. Gassas A, Zaidman I, Schechter T, Doyle J. Beyond gastrointestinal graft-versus-host disease. A lesson to learn. Pediatr Transplant. 2011; 15(7):E139-E141.

10. Han Y, Wu D, Sun A, et al. Selective embolization of the internal iliac arteries for the treatment of severe hemorrhagic cystitis following hematopoietic SCT. Bone Marrow Transplant. 2008;41(10):881-886.

11. Mahgerefteh SY, Sosna J, Bogot N, Shapira MY, Pappo O, Bloom AI. Radiologic imaging and intervention for gastrointestinal and hepatic complications of hematopoietic stem cell transplantation. Radiology. 2011;258(3):660-671.

12. Hayakawa J, Ueda T, Fujiwara Y, et al. Successful coil embolization for life-threatening hemorrhage in childhood leukemia induction therapy. Pediatr Int. 2013;55(2):248-251.

13. Li L, Li X, Fu P, Liu F. Recurrent gastrointestinal bleeding with ANCA associated glomerulonephritis successfully treated by transarterial embolization. Pak J Med Sci. 2013;29(6):1465-1467.

14. Moriarty JM, Xing M, Loh CT. Particle embolization to control lifethreatening hemorrhage from a fungating locally advanced breast carcinoma: a case report. J Med Case Rep. 2012;6:186.

15. Popiela TJ, Brzegowy P, Kibil W. Embolisation procedures in acute haemorrhage from lower gastrointestinal tract. Przegl Lek. 2013;70(5):303-307. Polish.

16. Rossetti A, Buchs NC, Breguet R, Bucher P, Terraz S, Morel P. Transarterial embolization in acute colonic bleeding: review of 11 years of experience and long-term results. Int J Colorectal Dis. 2013;28(6): 777-782.

17. Kim M, Song HJ, Kim S, et al. Massive life-threatening lower gastrointestinal hemorrhage caused by an internal hemorrhoid in a patient receiving antiplatelet therapy: a case report. Korean J Gastroenterol. 2012;60(4):253-257.
18. Lim WY, H'ng MW, Punamiya S. An uncommon case of haemorrhagic enteric fever treated successfully with super-selective embolisation using polyvinyl alcohol particles and coils. Singapore Med J. 2013; 54(3):e53-e55.

19. Mohd Rizal MY, Kosai NR, Sutton PA, et al. Arterial embolization of a bleeding gastric Dieulafoy lesion: a case report. Clin Ter. 2013; 164(1):25-27.

20. Rebibo L, Fuks D, Blot C, et al. Gastrointestinal bleeding complication of gastric fistula after sleeve gastrectomy: consider pseudoaneurysms. Surg Endosc. 2013;27(8):2849-2855.

21. So YH, Choi YH, Chung JW, Jae HJ, Song SY, Park JH. Selective embolization for post-endoscopic sphincterotomy bleeding: technical aspects and clinical efficacy. Korean J Radiol. 2012;13(1):73-81.

22. Urbano J, Manuel Cabrera J, Franco A, Alonso-Burgos A. Selective arterial embolization with ethylene-vinyl alcohol copolymer for control of massive lower gastrointestinal bleeding: feasibility and initial experience. J Vasc Interv Radiol. 2014;25(6):839-846.

23. Vrakas G, Pramateftakis MG, Raptis D, Kanellos D, Kanellos I. Selective embolization for massive upper gastrointestinal bleeding deriving from gastric angiodysplasia. J Surg Case Rep. 2012;2012(3):11.

24. Lenhart M, Paetzel C, Sackmann M, et al. Superselective arterial embolisation with a liquid polyvinyl alcohol copolymer in patients with acute gastrointestinal haemorrhage. Eur Radiol. 2010;20(8):1994-1999.
Patient Preference and Adherence

\section{Publish your work in this journal}

Patient Preference and Adherence is an international, peer-reviewed, open access journal that focuses on the growing importance of patient preference and adherence throughout the therapeutic continuum. Patient satisfaction, acceptability, quality of life, compliance, persistence and their role in developing new therapeutic modalities and compounds to optimize

\section{Dovepress}

clinical outcomes for existing disease states are major areas of interest for the journal. This journal has been accepted for indexing on PubMed Central. The manuscript management system is completely online and includes a very quick and fair peer-review system, which is all easy to use. Visit http://www. dovepress.com/testimonials.php to read real quotes from published authors. 